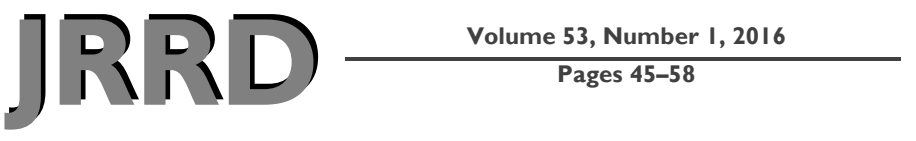

\title{
Fibromyalgia syndrome care of Iraq- and Afghanistan-deployed Veterans in Veterans Health Administration
}

\begin{abstract}
April F. Mohanty, MPH, PhD $;{ }^{1 *}$ Drew A. Helmer, MD, MS; ${ }^{2-3}$ Anusha Muthukutty, MS; ${ }^{1}$ Lisa M. McAndrew, PhD $;{ }^{2-4}$ Marjorie E. Carter, MSPH $;{ }^{1}$ Joshua Judd, MBA; ${ }^{1}$ Jennifer H. Garvin, PhD, MBA, RHIA, CTR, CPHQ, CCS, FAHIMA; ${ }^{1,5}$ Matthew H. Samore, MD ${ }^{1,5}$ Adi V. Gundlapalli, MD, PhD, MS ${ }^{1,5}$

${ }^{1}$ Informatics, Decision Enhancement, and Analytic Sciences (IDEAS) Center, Department of Veterans Affairs (VA) Salt Lake City Health Care System, Salt Lake City, UT; and Department of Internal Medicine, University of Utah School of Medicine, Salt Lake City, UT; ${ }^{2}$ War Related Illness and Injury Study Center, VA New Jersey Health Care System, East Orange, $N J ;{ }^{3}$ New Jersey Medical School, Rutgers University, Newark, NJ; ${ }^{4}$ Department of Educational and Counseling Psychology, University of Albany, Albany, NY; ${ }^{5}$ Department of Biomedical Informatics, University of Utah School of Medicine, Salt Lake City, UT
\end{abstract}

\begin{abstract}
Little is known regarding fibromyalgia syndrome (FMS) care among Operation Iraqi Freedom/Operation Enduring Freedom/Operation New Dawn (OIF/OEF/OND) Veterans. Current recommendations include interdisciplinary, teambased combined care approaches and limited opioid use. In this study of OIF/OEF/OND Veterans who accessed Veterans Health Administration services between 2002 and 2012, we hypothesized that combined care (defined as at least 4 primary care visits/yr with visits to mental health and/or rheumatology) versus $<4$ primary care visits/yr only would be associated with lower risk of at least 2 opioid prescriptions 12 mo following an FMS diagnosis. Using generalized linear models with a loglink, the Poisson family, and robust standard errors, we estimated risk ratios (RRs) and 95\% confidence intervals (CIs). We found that $1 \%$ of Veterans had at least 2 FMS diagnoses (International Classification of Diseases-9th Revision-Clinical Modification code 729.1) or at least 1 FMS diagnosis by rheumatology. Veterans with (vs without) FMS were more likely to be female, older, Hispanic, and never/currently married. Combined primary, mental health, and rheumatology care was associated with at least 2 opioid prescriptions (RR [95\% CI] for males 2.2 [1.1-4.4] and females 2.8 [0.4-18.6]). Also, combined care was associated with at least 2 nonopioid painrelated prescriptions, a practice supported by evidence-based clinical practice guidelines. In tandem, these results provide mixed evidence of benefit of combined care for FMS. Future studies of healthcare encounter characteristics, care coordination, and benefits for Veterans with FMS are needed.
\end{abstract}

Key words: Afghanistan, fibromyalgia syndrome, healthcare setting, healthcare utilization, Iraq, OIF/OEF/OND, opioid, primary care, PTSD, rheumatology, Veteran.

\section{INTRODUCTION}

The prevalence of fibromyalgia syndrome (FMS), a condition characterized primarily by widespread chronic musculoskeletal pain, has been estimated to range from

\footnotetext{
Abbreviations: $\mathrm{CI}=$ confidence interval, $\mathrm{DOD}=$ Department of Defense, DSS = Decision Support System, FMS = fibromyalgia syndrome, HSR\&D = Health Services Research and Development Service, ICD-9-CM = International Classification of Diseases-9th Revision-Clinical Modification, OIF/ $\mathrm{OEF} / \mathrm{OND}=$ Operation Iraqi Freedom/Operation Enduring Freedom/Operation New Dawn, PTSD = posttraumatic stress disorder, $\mathrm{RR}=$ risk ratio, $\mathrm{VA}=$ Department of Veterans Affairs, VHA = Veterans Health Administration, VINCI = VA Informatics Computing Infrastructure.

*Address all correspondence to April F. Mohanty, MPH, PhD; 500 Foothill Dr, Salt Lake City, UT 84148; 801-5821565, ext 1816; fax: 801-588-5939.

Email: april.mohanty@va.gov http://dx.doi.org/10.1682/JRRD.2014.10.0265
} 
1.0 to 6.0 percent in the U.S. civilian population [1-2]. Among U.S. Department of Defense (DOD) healthcare beneficiaries aged $<65 \mathrm{yr}$, a prevalence of 0.7 percent has been reported [3]. Females and older individuals are more likely to be diagnosed with FMS [3-5].

The prevalence and characteristics of Operation Iraqi Freedom/Operation Enduring Freedom/Operation New Dawn (OIF/OEF/OND) Veterans (both deployed and nondeployed) with FMS are unknown. There is also little research on the healthcare utilization of Veterans with FMS and possible variations in treatment across different healthcare providers and clinics within the Veterans Health Administration (VHA).

Generally, evidence-based practice guidelines recommend patient-tailored approaches that may include several nonpharmacologic and pharmacologic strategies to reduce symptoms and improve functionality [6-9]. Briefly, nonpharmacologic strategies include patient education, graded exercise, cognitive behavioral therapy, and complementary and alternative medicine therapies. Pharmacologic strategies include treatment with serotonin norepinephrine reuptake inhibitors, treatment with other nonopioid pain-related medications, and limited treatment with opioids. Guidelines also recommend interdisciplinary and integrative team-based approaches that include regular primary care visits and possible comanagement with mental health and rheumatology specialists [6-11]. Whether interdisciplinary, team-based combined care approaches are associated with best practices, e.g., less opioid use and more use of nonopioid pain-related medication, is unknown.

To support the implementation of evidence-based management of FMS in the VHA, we examined characteristics and healthcare utilization of OIF/OEF/OND Veterans with FMS. Our specific objectives were to describe sociodemographic and military characteristics of Veterans with FMS and to identify primary clinical sites of FMS diagnoses. Our secondary objective was to test the hypothesis that Veterans managed by an interdisciplinary, team-based approach of care for FMS (vs Veterans who are not) are less likely to be prescribed opioid medications and more likely to be prescribed nonopioid painrelated medications in the 12 mo following a FMS diagnosis. We defined a proxy variable for an interdisciplinary, team-based approach of care for FMS as combined utilization of regular primary care with mental health and/or rheumatology care within 12 mo of a diagnosis.

\section{METHODS}

\section{Study Setting}

Our cross-sectional study included Veterans from the national OIF/OEF/OND Roster file that is provided to the Department of Veterans Affairs (VA) Central Office Environmental Epidemiology Service by the Defense Manpower Data Center. The OIF/OEF/OND Roster includes Veterans who are a subset of military discharges identified as having VHA healthcare utilization. The OIF/OEF/OND Roster file was merged with data in the VA Informatics Computing Infrastructure (VINCI) [12]. These data include basic demographic files, clinical data, and all national inpatient and outpatient services provided to VHA healthcare users. Data for outpatient services in VHA include 6-digit Decision Support System (DSS) identifiers. These DSS identifiers are used to characterize outpatient clinic settings and are the single and critical designation by which VHA defines outpatient clinical work units for costing purposes [13]. The first 3 digits of the DSS identifier, or primary "stop code," designate the main clinical group responsible for patient care. The last 3 digits of the DSS identifier, or secondary "stop code," can be used by a VHA medical facility to further specify the main clinical group, for example, to specify the type of service provided or type of provider/ team that administered the care. The list of nationally standardized codes is reviewed and updated at least annually by VHA's National Stop Code Council, and lists of stop code changes and active stop codes as well as a current stop code instructional guide are posted on the DSS Identifier Web page.

\section{Participants}

The OIF/OEF/OND Roster included 647,288 male and 90,819 female Veterans who accessed VHA from fiscal years 2002-2012. Of these, we identified 15,420 male and 4,179 female Veterans who had $\geq 1$ outpatient diagnosis of FMS by the International Classification of Diseases9th Revision-Clinical Modification (ICD-9-CM) code 729.1: myalgia and myositis, unspecified. Researchers have cautioned that a single ICD-9-CM FMS diagnosis or diagnoses in nonrheumatology settings may have limited specificity to identify true FMS cases [1,14-15]. To improve the specificity of our FMS case definition and to be consistent with prior research of VHA administrative data [16], we only included Veterans who received $\geq 1$ FMS diagnosis in a rheumatology specialty care setting 
(identified by corresponding clinic stop code of 314) or $\geq 2$ FMS diagnoses on separate dates within $12 \mathrm{mo}$, regardless of outpatient care setting. There were 5,963 male and 2,245 female Veterans who met our FMS case definition.

\section{Outpatient Settings of Index FMS Diagnoses}

We defined the date of index FMS diagnosis to be the date of whichever came first: (1) the date of diagnosis in a rheumatology specialty care setting or (2) the first date of $\geq 2$ FMS diagnoses (on separate dates) within 12 mo. We used the term "index FMS date" to distinguish our analysis from one that examines incident FMS, since we did not determine whether Veterans were free of FMS before the index date. In addition to rheumatology, we examined the top 10 primary stop codes where an FMS diagnosis was coded, stratified by male and female Veterans, on the date of index FMS diagnosis.

\section{Exposure Definitions: Utilization of Primary Care and Mental Health and Rheumatology Specialty Care}

We classified primary care encounters to be any VHA visits with a primary stop code of $342,348,350$, or 323 , excluding secondary stop code 135 . We classified encounters by mental health to be any VHA visits with a primary stop code of 502-524, 527-599, or 725-731. Rheumatology specialty care visits were classified by any VHA visits with a primary stop code of 314 . Multiple visits for categories of primary care, mental health, or rheumatology were counted only if they occurred on separate dates. Follow-up by primary care, mental health, and/or rheumatology was examined 12 mo after the index FMS date. In the absence of an explicitly stated definition of regular primary care in the current VA/DOD Clinical Practice Guideline for the Management of Chronic Multisymptom Illness [17], we used an empirically derived definition for regular primary care as greater than or equal to the median number of visits over 12 mo of follow-up from the index date of FMS diagnosis.

\section{Outcome Definitions: Pharmacologic Outcomes}

We examined the number of uniquely dated prescriptions generated for opioid and nonopioid pain-related medications during the 12 mo after the index FMS date. A complete list of opioid and nonopioid pain-related medications included in our analyses is in Appendix 1 (available online only). We dichotomized users of opioid and nonopioid pain-related medications separately using a cutoff of $\geq 2$ uniquely dated prescriptions in the $12 \mathrm{mo}$ after the index FMS date.

\section{Definitions of Potential Confounding Variables}

\section{Sociodemographic and Military Service Characteristics}

We examined sociodemographic characteristics including age, race, marital status, and education. We reported age at date of first VHA encounter and age at index FMS date. We also examined factors related to Veterans' military service component (Active Duty vs reserve), rank, and branch of service.

\section{Mental Health Comorbidities}

Because mental health diagnoses of anxiety, posttraumatic stress disorder (PTSD), and depression have been associated with FMS and are risk factors for opioid prescriptions [18], we examined these mental health diagnoses associated with outpatient encounters during the 12 mo following the index FMS date. We used ICD9-CM diagnostic codes 300.00-300.09, 300.20-300.29, and 300.3 to categorize anxiety; code 309.81 to categorize PTSD; and codes 296.20-296.25, 296.30-296.36, 300.4 , and 311 to categorize depression diagnoses according to a previously published study of mental health diagnoses in the OIF/OEF/OND Veteran population [19]. These represent a cluster of mood and anxiety disorders that most prior FMS research has focused on [20-21], but it is not an exhaustive list. Others include conversion and bipolar disorder, which are not the focus of this current study [22-23].

\section{Charlson Comorbidity Index}

The Charlson Comorbidity Index is a validated measure of the number and severity of coexisting diagnoses. For each Veteran with FMS, we calculated the Charlson Comorbidity Index [12] using ICD-9-CM diagnostic codes related to inpatient and outpatient encounters during the 12 mo following the index FMS date [24].

\section{Statistical Analysis}

We examined frequency distributions of sociodemographic and military service characteristics among Veterans who met our FMS case definition and Veterans who had no FMS diagnoses from fiscal years 2002-2012, stratified by sex. We used the Pearson chi-square test to examine statistically significant differences in the distribution of these characteristics.

We examined associations between combined utilization of regular primary care with mental health and/or rheumatology care as a proxy for an interdisciplinary, 
team-based approach (vs only primary care utilization) and the risk of $\geq 2$ opioid or $\geq 2$ nonopioid pain-related prescriptions in the 12 mo following the index FMS diagnosis. We restricted our analysis to Veterans with $\geq 1$ primary care visit during the 12 mo of follow-up to avoid including Veterans who may have sought care only outside of the VHA. To examine these associations, we fit generalized linear models with a log-link, Poisson family (a log-Poisson regression model), and robust standard errors to estimate risk ratios (RRs) and 95 percent confidence intervals (CIs). The log-Poisson regression model with robust standard errors allows estimation of RRs for prospective studies with binary outcome data [25].

The following potential confounding variables were identified a priori and were included in all adjusted models, including Model 1: number of anxiety, PTSD, and depression diagnoses during the 12 mo after index FMS date and nonreferent indicator variables (i.e., dummy variables that excluded the reference category) for each mental health disorder (1, 2, and $\geq 3$ diagnoses). We also adjusted for the Charlson Comorbidity Index ( 2 nonreferent indicator variables: 1 and $\geq 2$ ). We used indicator variables to allow flexibility for fitting potential nonlinear associations. In Model 2, we additionally adjusted for sociodemographic and military characteristic variables: age at index FMS date ( 2 nonreferent indicator variables: $>30-40$ and $>40$ ); white, non-Hispanic race/ ethnicity; married marital status; and greater than high school education as well as Active Duty status and branch of service (4 nonreferent indicator variables: Air Force, Navy, Marines Corps, and Coast Guard).

There have been temporal changes in the "VA/DOD Clinical Practice Guideline for the Management of Opioid Therapy for Chronic Pain" [26-27]. These may have resulted in changes to FMS management, including prescribing practices of opioid and nonopioid pain-related medications. We explored whether our results were sensitive to the adjustment for the year of index FMS diagnosis by including 10 nonreferent indicator variables for calendar years 2002-2011 [3,28]. We also explored whether adjustment for the index FMS setting (whether in a rheumatology setting) materially altered our results. Researchers have advised that for mental health diagnoses determined by ICD-9-CM codes, those who only have one diagnosis code may not truly have the mental health diagnosis [16]. To address this potential limitation, we also explored whether results for Model 1 were sensitive to recoding of individuals who had only one ICD-9-
CM code corresponding to anxiety, PTSD, or depression as having no diagnosis.

All $p$-values were two-sided and defined to be significant at $p<0.01$. All analyses were conducted using Stata software (version 12.1, StataCorp; College Station, Texas).

\section{RESULTS}

\section{Prevalence and Characteristics of Veterans with FMS}

The prevalence of FMS was higher among female than male Veterans. There were 5,963 (0.9\%) male and 2,245 $(2.5 \%)$ female Veterans, or 1 percent of male and female Veterans combined, with prevalent FMS according to our case definition among OIF/OEF/OND Veterans who had $\geq 1$ VHA encounter from fiscal years 2002-2012. Compared with the 631,868 male and 86,640 female Veterans who did not have a FMS diagnosis during the $10 \mathrm{yr}$ study period, Veterans with FMS were older, more likely to be Hispanic, and never or currently married, regardless of sex (Table 1). Females with FMS were more likely to have attained more than a high school education and to have served in the Air Force than females without FMS. Males with FMS were more likely to have served in the Army than males without FMS.

\section{Outpatient Settings of Index FMS Diagnosis}

Over a quarter of FMS diagnoses were documented in a primary care setting (24\% for male and $29 \%$ for female Veterans) (Table 2). The other top five settings were similar for FMS diagnoses across male and female Veterans, including chiropractic care, physical medicine and rehabilitation, and rheumatology/arthritis specialty care settings. Eight percent of female Veterans with FMS received an index diagnosis in women's health-related specialty clinic settings. A higher proportion of male $(11 \%)$ versus female $(6 \%)$ Veterans received their index FMS diagnosis in a pain specialty clinic.

\section{Utilization of Primary Care and Mental Health and Rheumatology Specialty Care}

Among 4,855 male and 1,786 female Veterans with at least 12 mo of follow-up after their FMS index date, most male $(n=4,441[91 \%])$ and female $(n=1,526$ [85\%]) Veterans had $\geq 1$ primary care encounter. Also, most male $(n=3,437$ [71\%]) and female $(n=1,299$ [73\%]) Veterans had $\geq 1$ mental health encounter. Fewer 
Table 1.

Sociodemographic and military service characteristics among Veterans, returned from Iraq and Afghanistan, who accessed Veterans Health Administration (VHA) care during fiscal years 2002-2012. Data presented as $n(\%)$.

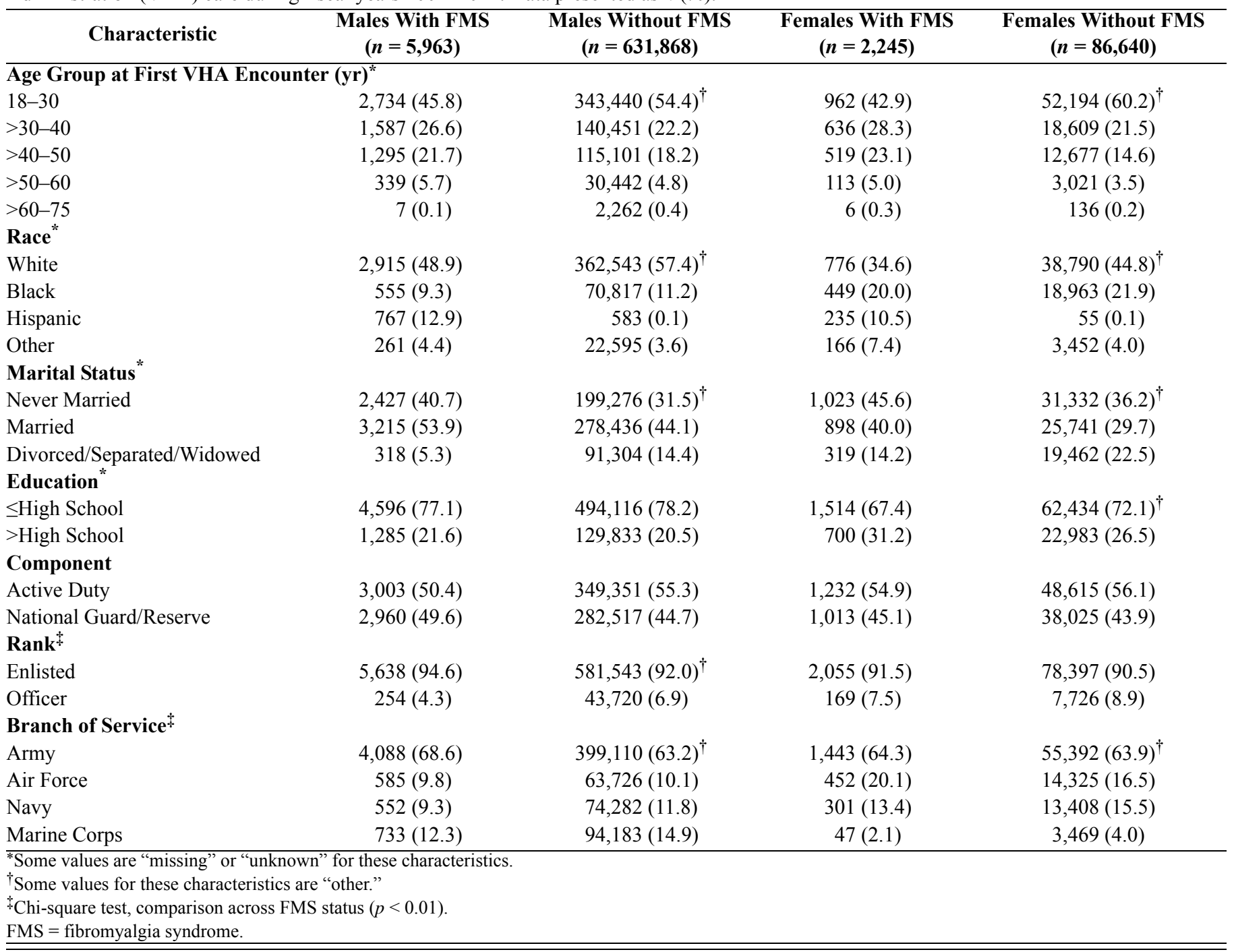

male $(n=733[15 \%])$ and female $(n=516$ [29\%]) Veterans had $\geq 1$ follow-up rheumatology specialty care visit.

For the 4,441 male and 1,526 female Veterans who had $\geq 1$ primary care visit during the 12 mo following their index FMS diagnosis date, the median (range) of primary care encounters for male and female Veterans was 4 (1-54) and 4 (1-61) visits, respectively. The median (range) of mental health encounters for male and female Veterans was $5(0-231)$ and $6(0-183)$ visits, respectively. For rheumatology care encounters 12 mo following index FMS diagnosis date, the median (range) for male and female Veterans was $0(0-13)$ and $0(0-15)$ visits, respectively. Most Veterans $(\sim 80 \%)$ received a combination of primary care and mental health or a combination of primary care and rheumatology care (Table $3)$. A higher proportion of female $(n=357$ [23\%]) than male $(n=531[12 \%])$ Veterans received a combination of care from all three settings.

\section{Associations of Combined Primary Care with Mental Health and/or Rheumatology Utilization and Pain- Related Medication Prescriptions}

There were 1,830 (41\%) males and 589 (39\%) females who received $\geq 1$ opioid prescription among Veterans with $\geq 1$ primary care visit during the 12 mo following their index FMS diagnosis date. Most Veterans received 
Table 2.

Top 10 fibromyalgia syndrome (FMS) outpatient care settings corresponding to index FMS diagnosis, restricted to Veterans who only had one unique stop code.

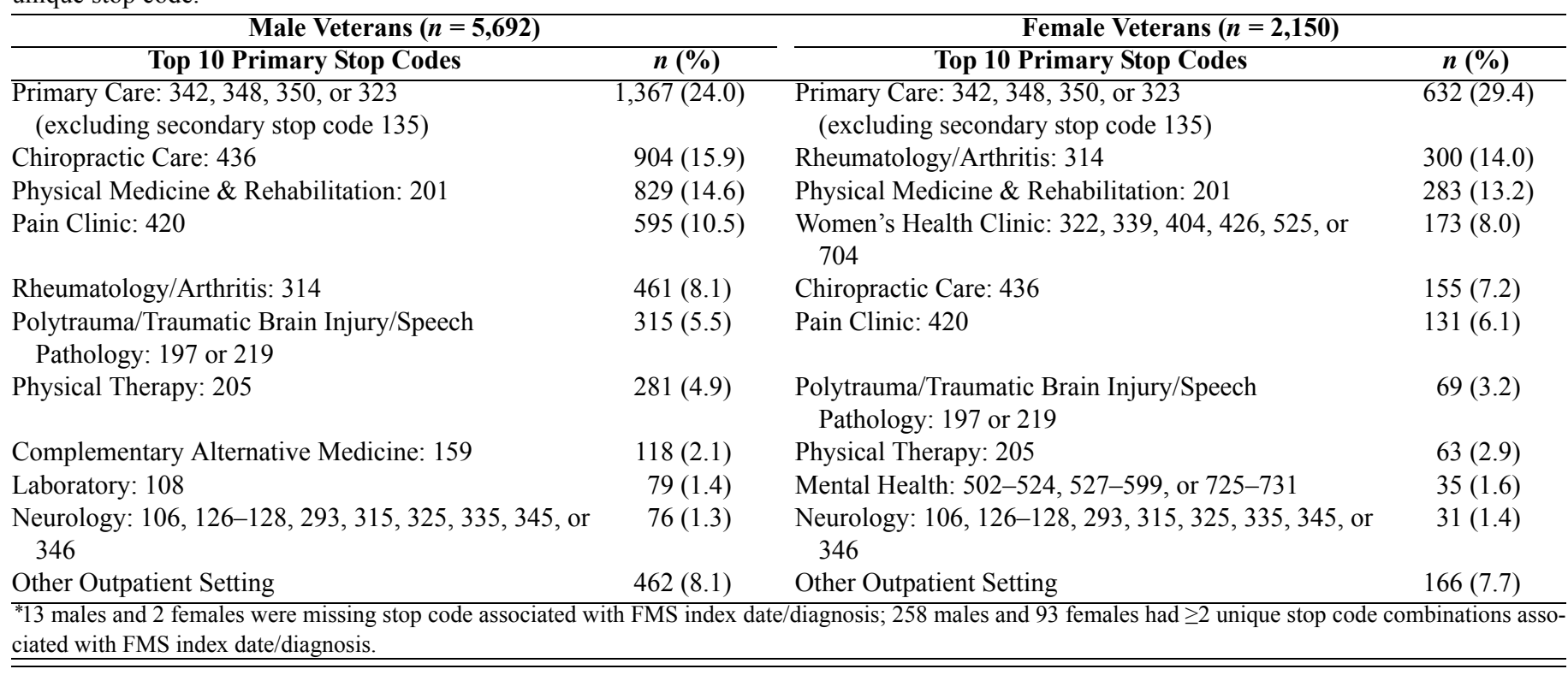

Table 3.

Primary care, mental health, and rheumatology utilization 12 mo after index fibromyalgia syndrome date among Veterans who had at $\geq 1$ primary care follow-up visit.

\begin{tabular}{|c|c|c|}
\hline Care Setting & $\begin{array}{c}\text { Male Veterans } \\
(n=4,441)\end{array}$ & $\begin{array}{l}\text { Female Veterans } \\
(n=1,526)\end{array}$ \\
\hline Primary Care Only $(n)$ & $1,055(23.8)$ & $288(18.9)$ \\
\hline$<4$ Visits $(\%)$, reference category & $695(15.6)$ & $173(11.3)$ \\
\hline$\geq 4$ Visits $(\%)$ & $360(8.1)$ & $115(7.5)$ \\
\hline Primary Care \& Mental Health, No Rheumatology $(n)$ & $2,706(60.9)$ & $787(51.6)$ \\
\hline$<4$ Primary Care Visits $(\%)$ & $1,135(25.6)$ & $336(22.0)$ \\
\hline$\geq 4$ Primary Care Visits $(\%)$ & $1,571(35.4)$ & $451(30.0)$ \\
\hline Primary Care \& Rheumatology, No Mental Health $(n)$ & $149(3.4)$ & $94(6.2)$ \\
\hline$<4$ Primary Care Visits $(\%)$ & $88(2.0)$ & $52(3.4)$ \\
\hline$\geq 4$ Primary Care Visits $(\%)$ & $61(1.4)$ & $42(2.8)$ \\
\hline Combined Primary Care, Mental Health, \& Rheumatology $(n)$ & $531(12.0)$ & $357(23.4)$ \\
\hline$<4$ Primary Care Visits $(\%)$ & $186(4.2)$ & $124(8.1)$ \\
\hline$\geq 4$ Primary Care Visits (\%) & $345(7.8)$ & $233(15.3)$ \\
\hline
\end{tabular}

$\geq 1$ nonopioid pain-related prescription: 3,017 (68\%) males and 1,124 (74\%) females. The median (range) of opioid prescriptions for male and female Veterans was 3 (1-42) and 2 (1-26), respectively. The median (range) of nonopioid pain-related prescriptions for male and female Veterans was 2 (1-20) and 2 (1-21), respectively.

Contrary to our primary hypothesis, we found that compared with $<4$ primary care visits (i.e., less than regu- lar primary care), combined regular primary care, mental health, and rheumatology utilization was associated with $\geq 2$ opioid prescriptions: RRs and 95 percent CIs for male and female Veterans were $2.22(1.13-4.39)$ and 2.79 (0.42-18.62), respectively, for the fully adjusted model (Model 2, Tables 4-5).

Supporting our secondary hypothesis, we did find evidence that compared with Veterans who received less 
Table 4.

Associations of combined regular primary care and mental health and/or rheumatology utilization and pain-related medication prescriptions (opioid or nonopioid) 12 mo following index fibromyalgia syndrome (FMS) diagnosis date among male Veterans $(n=4,441)$.

\begin{tabular}{|c|c|c|c|c|c|}
\hline Model Variable & $\begin{array}{c}<4 \text { PC } \\
\text { Visits Only }\end{array}$ & $\begin{array}{c}\geq 4 \text { PC } \\
\text { Visits Only }\end{array}$ & $\begin{array}{c}\geq 4 \mathrm{PC} \\
\text { Visits \& MH }\end{array}$ & $\begin{array}{c}\geq 4 \text { PC } \\
\text { Visits \& RH }\end{array}$ & $\begin{array}{c}\geq 4 \text { PC Visits, } \\
\text { MH \& RH }\end{array}$ \\
\hline $\begin{array}{l}\text { No. with } \geq 2 \text { Opioid } R x \\
\text { RR }(95 \% \text { CI })\end{array}$ & 75 & 78 & 662 & 9 & 151 \\
\hline Unadjusted & 1.0 (reference) & $2.01(1.50-2.68)$ & $3.90(3.13-4.87)$ & $1.37(0.72-2.59)$ & $4.06(3.17-5.18)$ \\
\hline Model $1^{*}$ & 1.0 (reference) & $1.40(0.71-2.75)$ & $1.77(1.06-2.98)$ & $0.97(0.26-3.58)$ & $1.82(1.07-3.09)$ \\
\hline Model $2^{\dagger}$ & 1.0 (reference) & $2.02(0.89-4.57)$ & $2.20(1.13-4.29)$ & $1.04(0.17-6.45)$ & $2.22(1.13-4.39)$ \\
\hline Unadjusted & 1.0 (reference) & $2.19(1.58-3.04)$ & $7.51(5.86-9.61)$ & $3.86(2.50-5.96)$ & $8.37(6.49-10.78)$ \\
\hline Model $1^{*}$ & 1.0 (reference) & $2.60(1.14-5.91)$ & $4.50(2.21-9.15)$ & $2.37(0.71-7.89)$ & $4.92(2.41-10.05)$ \\
\hline Model $2^{\dagger}$ & 1.0 (reference) & $3.42(0.98-11.88)$ & $6.99(2.32-21.09)$ & $2.02(0.27-15.11)$ & $7.79(2.57-23.57)$ \\
\hline $\begin{array}{l}\text { "Model } 1 \text { is adjusted for no. anx } \\
\text { Comorbidity Index }(1, \geq 2) \text {; each } \\
\text { 'Model } 2 \text { adjusts for same varia } \\
\text { Hispanic race/ethnicity, married } \\
\text { Air Force, Navy, Marine Corps, } \\
C I=\text { confidence intral }\end{array}$ & $\begin{array}{l}\text { Model } 1 \text { in addi } \\
\text { al status, greater } t \\
\text { Guard). }\end{array}$ & $\begin{array}{l}\text { lo. posttraumatic stress } \\
\text { licator variable. } \\
\text { to sociodemographic } \\
\text { high school education, }\end{array}$ & $\begin{array}{l}\text { bles: age at FMS in } \\
\text { military characteris }\end{array}$ & $\begin{array}{l}\text { e ( } 2 \text { indicator variab } \\
\text { tive Duty, branch of }\end{array}$ & $(1,2, \geq 3)$, and Charlso \\
\hline
\end{tabular}

Table 5.

Associations of combined primary care and mental health and/or rheumatology utilization and pain-related medication prescriptions (opioid or nonopioid) 12 mo following index fibromyalgia syndrome (FMS) diagnosis date among female Veterans $(n=1,526)$.

\begin{tabular}{|c|c|c|c|c|c|}
\hline Model Variable & $\begin{array}{c}<4 \text { PC } \\
\text { Visits Only }\end{array}$ & $\begin{array}{c}\geq 4 \text { PC } \\
\text { Visits Only }\end{array}$ & $\begin{array}{c}\geq 4 \text { PC } \\
\text { Visits \& MH }\end{array}$ & $\begin{array}{c}\geq 4 \text { PC } \\
\text { Visits \& RH }\end{array}$ & $\begin{array}{c}\geq 4 \text { PC Visits, } \\
\text { MH \& RH }\end{array}$ \\
\hline No. at Risk & 173 & 115 & 451 & 42 & 233 \\
\hline No. with $\geq 2$ Opioid $R x$ & 14 & 21 & 155 & 10 & 78 \\
\hline \multicolumn{6}{|l|}{$\mathrm{RR}(95 \% \mathrm{CI})$} \\
\hline Unadjusted & 1.0 (reference) & $2.26(1.20-4.25)$ & $4.25(2.53-7.13)$ & $2.94(1.41-6.16)$ & $4.14(2.43-7.06)$ \\
\hline Model $1^{*}$ & 1.0 (reference) & $2.59(0.28-23.57)$ & $3.95(0.61-25.67)$ & -+ & $3.89(0.60-25.50)$ \\
\hline Model $2^{\dagger}$ & 1.0 (reference) & $2.12(0.24-18.55)$ & $2.95(0.45-19.30)$ & -+ & $2.79(0.42-18.62)$ \\
\hline $\begin{array}{l}\text { No. with } \geq 2 \text { Nonopioid } R x \\
\text { RR }(95 \% \text { CI) }\end{array}$ & 24 & 27 & 300 & 16 & 169 \\
\hline Unadjusted & 1.0 (reference) & $1.69(1.03-2.78)$ & $4.79(3.29-6.99)$ & $2.75(1.61-4.69)$ & $5.23(3.58-7.64)$ \\
\hline Model $1^{*}$ & 1.0 (reference) & $1.65(0.44-6.14)$ & $3.15(1.14-8.77)$ & $1.91(0.50-7.36)$ & $3.38(1.22-9.41)$ \\
\hline Model $2^{\dagger}$ & 1.0 (reference) & $1.03(0.26-4.12)$ & $2.19(0.82-5.87)$ & $0.85(0.21-3.45)$ & $2.32(0.87-6.21)$ \\
\hline $\begin{array}{l}\text { "Model } 1 \text { is adjusted for no. anxi } \\
\text { Comorbidity Index }(1, \geq 2) \text {; each } \\
\text { 'Model } 2 \text { adjusts for same variab } \\
\text { Hispanic race/ethnicity, married } \\
\text { Air Force, Navy, Marine Corps, } \\
\text { \$Too few events limited risk estin }\end{array}$ & $\begin{array}{l}\text { diagnoses }(1,2, \geq 3 \\
\text { e is included as an } \\
\text { in Model } 1 \text { in additi } \\
\text { tal status, greater th } \\
\text { st Guard). } \\
\text { on. }\end{array}$ & $\begin{array}{l}\text { no. posttraumatic stress } \\
\text { licator variable. } \\
\text { to sociodemographic v } \\
\text { high school education, }\end{array}$ & $\begin{array}{l}\text { order diagnoses }(1,2 \text {, } \\
\text { ables: age at FMS inde } \\
\text { military characteristic }\end{array}$ & $\begin{array}{l}\text { no. depression diagn } \\
\text { ( } 2 \text { indicator variabl } \\
\text { tive Duty, branch of }\end{array}$ & $\begin{array}{l}(1,2, \geq 3) \text {, and Charlsor } \\
30-40,>40) \text {, white non } \\
\text { ice ( } 4 \text { indicator variables }\end{array}$ \\
\hline $\mathrm{CI}=$ confidence interval, $\mathrm{MH}=\mathrm{n}$ & 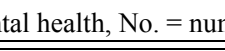 & , $\mathrm{PC}=$ primary care, & $=$ rheumatology, $\mathrm{RR}=$ & tio, $\mathrm{Rx}=$ prescrip & \\
\hline
\end{tabular}

than regular primary care $(<4$ primary care visits in the 12 mo after index FMS date), combined regular primary care, mental health, and rheumatology utilization was associated with $\geq 2$ nonopioid pain-related prescriptions: RRs and 95 percent CIs for male and female Veterans were $7.79(2.57-23.57)$ and 2.32 (0.87-6.21), respectively, for the fully adjusted model (Model 2, Tables 4-5).
These results were not materially altered when we further adjusted for the year of index FMS diagnosis and whether the index diagnosis was in a rheumatology setting (Appendix 2, available online only). Also, our results were robust to recoding of individuals with one diagnosis of anxiety, PTSD, or depression to having no diagnosis for these conditions. 


\section{DISCUSSION}

To the best of our knowledge, this is the first study to report the prevalence and related sociodemographic and military characteristics of FMS among national OIF/OEF/ OND Veterans. We report a $10 \mathrm{yr}$ FMS prevalence of 0.9 percent among males and 2.4 percent among females who accessed the VHA. Over a quarter of FMS diagnoses were documented in a primary care setting. Compared with Veterans without FMS, Veterans with FMS were more likely to be female, older, never/currently married, and to have served in the Army (males) or Air Force (females). One year following index FMS diagnosis, most Veterans sought a combination of primary care and mental health and/or rheumatology. Contrary to our primary hypothesis, Veterans with FMS with regular primary care visits combined with mental health and rheumatology visits were more likely to be prescribed $\geq 2$ opioids during the 12 mo following index FMS diagnosis. Combined care was also associated with $\geq 2$ nonopioid pain-related prescriptions.

The prevalence of FMS in our study of OIF/OEF/OND Veterans was within the range reported in studies of civilian [1] and military populations [3]. Researchers have reported that among Gulf war Veterans, deployment (versus nondeployment) may be associated with a doubling of the risk of FMS (odds ratio 2.32 [95\% CI: 1.02-5.27]) [29]. The present study did not examine the association between deployment and FMS diagnosis. Other characteristics that we found to be related to FMS diagnoses were consistent with prior studies, including older age and female sex $[1,3,5,14]$. The FMS-female sex association is worth noting because women continue to be one of the fastest growing subsets of VHA users [30]. We are unaware of prior studies that report a higher prevalence of FMS among those of Hispanic ethnicity, though there are limited investigations of race/ethnicity and FMS. Studies of chronic pain in general support that Hispanic and African American race/ethnicities are at greater risk of experiencing pain, but it is unclear that these differences remain after controlling for other confounding variables [31]. If our findings are replicated, they may provide evidence for potential disparities in the experience of FMS and FMS management among ethnic minorities. Identification of disparities in pain and pain management has been highlighted as an area of needed future research in the Institute of Medicine's "Relieving Pain in America: A Blueprint for
Transforming Prevention, Care, Education and Research" [32].

Consistent with a prior non-VHA study of FMS, FMS diagnoses were most common in primary care [15]. In our study of the VHA, other predominant nonrheumatology clinical settings of FMS diagnoses included chiropractic care, physical medicine and rehabilitation, and pain clinics. Also, among females, women's healthrelated clinics were one of the top five settings of FMS diagnoses. Since most diagnoses of FMS occur outside the rheumatology setting, it may be important to ensure that clinicians in these settings are made aware of and trained in the latest evidence-based practice guidelines for diagnosing and managing FMS and that procedures are in place for timely referrals to rheumatology, especially if a diagnosis is elusive [10]. Some experts recommend that rheumatologists train primary care colleagues on the recognition of FMS [33].

Investigators have demonstrated that patients with FMS in both civilian and military populations have higher utilization of healthcare. Berger et al. reported that compared with civilians without FMS, those with FMS had twice as many outpatient and four times as many emergency room visits over 12 mo [14]. Other investigators have reported that utilization of healthcare is higher for FMS than other chronic medically unexplained symptoms among military personnel, including irritable bowel syndrome and chronic fatigue syndrome [3]. Therefore, it may not be surprising that in the present study most Veterans sought a combination of primary care and mental health and/or rheumatology specialty care 12 mo following their index FMS diagnosis; this was especially evident for combined primary care with mental health.

Whether utilization of combined care in our study is a reflection of a guideline-recommended, interdisciplinary, team-based approach; comorbid diagnoses; and/or challenges related to identifying and managing FMS is uncertain. On the one hand, FMS is known to be associated with a number of comorbid conditions; seven conditions were reported by investigators of a civilian population-based study, including depression, anxiety, headache, irritable bowel syndrome, chronic fatigue syndrome, systemic lupus erythematous, and rheumatoid arthritis [5]. Each of these conditions was 2 to 7 times more likely to be present in patients with FMS than patients without FMS. PTSD is another condition that is often comorbid with FMS and highly prevalent in the OIF/OEF/OND Veteran population [11,34-37]. While we 
did not examine all reported comorbid conditions of FMS, we did examine mental health-related conditions. The prevalence of $\geq 1$ diagnosis for anxiety, PTSD, and depression 12 mo following index FMS date was 21.5, 51.0 , and 21.0 percent, respectively. Restricting to individuals with $\geq 2$ diagnoses reduced these prevalence estimates by 5 percent. The combined utilization of primary care with mental health among Veterans in our study may be expected given the high prevalence of mental health conditions. On the other hand, combined care may be a reflection of high healthcare utilization overall, which may indicate complexity of the patients, poor coordination of care, and challenges related to diagnosing FMS $[7,10,38]$. We did not examine overall healthcare utilization of Veterans seeking combined care (vs those with primary care visits only), nor could we examine the reasons for follow-up utilization. As a result, it is unclear whether combined utilization represents recommended interdisciplinary, team-based approaches for managing FMS; higher utilization of services to independently address the multiple comorbid conditions [11]; or perhaps overutilization of VHA care. Lastly we note that stop codes, for mental health services in particular, likely reflect various levels of interdisciplinary and integrative treatment, which the current study could not examine.

We sought empiric evidence to support the clinical practice guideline recommendations that combined care is associated with best practices, i.e., less opioid use and more use of nonopioid pain-related medication. Contrary to our first hypothesis, results support associations of combined care with a higher risk of receiving $\geq 2$ opioid prescriptions. We note that this finding is correlational, and we are unable to infer a direction of causality. Bearing this in mind, there are several potential explanations for our findings. The association between indicators of combined care and opioid therapy is consistent with clinical practice guidelines for opioid therapy [28]. Also, it may be that patients who receive opioid therapy are those with more complex, severe, and treatment-refractory conditions. Thus, the evidence for an association between combined care and opioid therapy may be consistent with a prior escalation of care in the service of attempting to better manage pain.

Our study robustly supports the hypothesis that Veterans with utilization of mental health and rheumatology in addition to regular primary care are more likely to be prescribed $\geq 2$ nonopioid pain-related medications (guideline-adherent practice). For instance, when we explored a change in our reference category to "only regular primary care" users (rather than less than "only regular primary care" users), associations between combined regular primary care, mental health, and rheumatology utilization and $\geq 2$ nonopioid pain-related medications remained statistically significant (Appendix 2, Model 2). In contrast, there is less evidence supporting that Veterans with combined care are more likely to be prescribed opioids (not consistent with guideline recommendations). When we explored a change in our reference category to "only regular primary care" users, the association of combined care and opioid use was no longer statistically significant. Thus, it may be that regular or greater primary care utilization (compared with less than regular primary care utilization) and not combined care per se is associated with higher likelihood of being prescribed opioids, perhaps due to other indications for opioid prescription and the necessary, regular encounters to responsibly manage the opioid use.

\section{LIMITATIONS}

As with all studies that rely on administrative data, there is the potential for misclassification of FMS. Since we were interested in focusing our analyses on Veterans with true diagnoses of FMS, we required that Veterans have $\geq 2$ ICD-9-CM diagnoses of FMS in a 12 mo period or $\geq 1$ diagnosis in a rheumatology specialty care setting. Although this definition has not been examined for validity in the OIF/OEF/OND Veteran population, similar definitions have been used in studies of military personnel and our prevalence estimates in male and female Veterans are similar to those reported previously [3]. Another weakness was that we were unable to determine the incident date of FMS diagnosis, which precluded analyses of causal relationships and limited our interpretation of temporal relationships. We relied on an index FMS diagnosis date, the first documentation of FMS in VHA diagnosis codes over the study period.

Interpretation of the results related to the examination of healthcare utilization and treatment during the 12 mo following the index FMS date should be made in the context of several potential limitations. These include use of combined utilization of regular primary care with mental health and/or rheumatology care as a proxy for an interdisciplinary, team-based approach to FMS care. We are uncertain whether this proxy is appropriate or 
whether it is a reflection of escalated care utilization driven by patient need that is not interdisciplinary or integrative in nature. Since we did not examine reasons (including diagnoses) related to follow-up primary care, mental health, and rheumatology visits, we cannot make strong assertions regarding the potential benefit or harm of combined care for FMS. Second, we did not account for the potential variability in the specific knowledge or clinical expertise of the providers, which may be a valuable area for future research. Third, since we were unable to identify an explicit definition of regular primary care for FMS in the current "VA/DOD Clinical Practice Guideline for the Management of Chronic Multisymptom Illness" [17], we used the median number of visits in $12 \mathrm{mo}, \geq 4$ primary care visits, to define "regular primary care," which may not be clinically relevant or may have limited generalizability. We note that our definition of "regular primary care" as $\geq 4$ primary care visits/yr is consistent with some previous studies of management of somatoform disorders [39]. Fourth, although we attempted to control for potential confounding variables, there may be residual confounding, which if present would bias our estimates of risk. To ensure that we had adequate power to estimate RRs, we used the medians (among Veterans with medication use) for analyses of pain-related medication associations. However, especially for the analyses of opioids, a more clinically relevant outcome may be chronic use. Because we did not have details on dose or longitudinal duration of continued or intermittent treatment, we were unable to examine chronic use. Also, we used prescription history as noted in the electronic medical record as an indicator for medication use; we did not determine whether patients actually consumed their medications or how adherent they were to prescription instructions. We were unable to examine the clinical indication for the medication prescriptions. For example, some of the nonopioid painrelated medications, antidepressants and gabapentinoids, in particular, may have been prescribed for the management of nonpain medical and mental health comorbidities that are common among patients with FMS. There may have been losses to follow-up, which could introduce selection bias, although we attempted to address this by including only Veterans with $\geq 1$ primary care visit through the VHA during the 12 mo following FMS index date. Future investigations are needed to examine other guideline-recommended treatments for FMS, including patient education, graded exercise, cognitive behavioral therapy, and complementary and alternative medicine therapies.

\section{CONCLUSIONS}

Our present study extends the current scope of research on FMS to include OIF/OEF/OND Veterans who access VHA. Our study confirmed several previously identified risk factors for FMS and identified potential new risk factors (e.g., Hispanic ethnicity) that warrant further investigation. Contrary to our hypothesis, Veterans with FMS who utilized regular primary care, mental health, and rheumatology (combined care) were more likely to be prescribed opioids. However, closer examination suggests that regular primary care (relative to less than regular primary care) is driving the association. Combined care was also associated with $\geq 2$ nonopioid pain-related prescriptions; unlike the findings for opioid medications, results were not materially altered in our sensitivity and exploratory analyses. Future studies are needed to more closely examine associations of interdisciplinary, team-based approaches to FMS care, overall VHA utilization, and recommendations for FMS treatment. Such studies can support the implementation of evidence-based management of FMS in VHA.

\section{ACKNOWLEDGMENTS}

\author{
Author Contributions: \\ Study design: A. F. Mohanty, D. A. Helmer, L. M. McAndrew, \\ J. H. Garvin, A. V. Gundlapalli. \\ Conceptualized research question: A. F. Mohanty, D. A. Helmer, \\ L. M. McAndrew, M. H. Samore, A. V. Gundlapalli. \\ Acquisition of data: A. Muthukutty, M. E. Carter, J. Judd. \\ Analysis and interpretation of data: A. F. Mohanty, A. Muthukutty, \\ D. A. Helmer, A. V. Gundlapalli. \\ Drafting of manuscript: A. F. Mohanty. \\ Critical revision of manuscript for important intellectual content: \\ D. A. Helmer, L. M. McAndrew, A. V. Gundlapalli.
}

Financial Disclosures: The authors have declared that no competing interests exist.

Funding/Support: This material was based on work supported by the VA Office of Research and Development, Health Services Research and Development Service (HSR\&D) (project no. HIR 10-001) (principal investigator: Samore). Dr. Mohanty is supported by the VA Advanced Fellowship Program in Medical Informatics of the Office of Academic Affiliations. Dr. McAndrew is supported by an HSR\&D Career Development Award (award \#CDA13-017).

Additional Contributions: Resources and administrative support were provided by the VA Salt Lake City Health Care System (IDEAS 
Center 2.0) and the War Related Illness and Injury Study Center, a field program of the VA Office of Public Health at VA New Jersey Health Care System. We would like to acknowledge our research team members and the VINCI team in Salt Lake City.

Institutional Review: The University of Utah Institutional Review Board and the VA Salt Lake City Health Care System Research and Development Committee approved the protocol for this study.

Participant Follow-Up: The authors have no plans to notify the study subjects of the publication of this article because of a lack of contact information.

Disclaimer: The views expressed are those of the authors and do not necessarily represent the views or opinions of the U.S. Government or the VA.

\section{REFERENCES}

1. Vincent A, Lahr BD, Wolfe F, Clauw DJ, Whipple MO, Oh TH, Barton DL, St Sauver J. Prevalence of fibromyalgia: A population-based study in Olmsted County, Minnesota, utilizing the Rochester Epidemiology Project. Arthritis Care Res (Hoboken). 2013;65(5):786-92. [PMID:23203795] http://dx.doi.org/10.1002/acr.21896

2. Wolfe F, Ross K, Anderson J, Russell IJ, Hebert L. The prevalence and characteristics of fibromyalgia in the general population. Arthritis Rheum. 1995;38(1):19-28.

[PMID:7818567] http://dx.doi.org/10.1002/art.1780380104

3. Jeffery DD, Bulathsinhala L, Kroc M, Dorris J. Prevalence, health care utilization, and costs of fibromyalgia, irritable bowel, and chronic fatigue syndromes in the military health system, 2006-2010. Mil Med. 2014;179(9):1021-29. [PMID:25181721] http://dx.doi.org/10.7205/MILMED-D-13-00419

4. Weimer MB, Macey TA, Nicolaidis C, Dobscha SK, Duckart JP, Morasco BJ. Sex differences in the medical care of VA patients with chronic non-cancer pain. Pain Med. 2013; 14(12):1839-47. [PMID:23802846] http://dx.doi.org/10.1111/pme.12177

5. Weir PT, Harlan GA, Nkoy FL, Jones SS, Hegmann KT, Gren LH, Lyon JL. The incidence of fibromyalgia and its associated comorbidities: A population-based retrospective cohort study based on International Classification of Diseases, 9th Revision codes. J Clin Rheumatol. 2006;12(3): 124-28. [PMID:16755239] http://dx.doi.org/10.1097/01.rhu.0000221817.46231.18

6. Ablin J, Fitzcharles MA, Buskila D, Shir Y, Sommer C, Häuser W. Treatment of fibromyalgia syndrome: Recommendations of recent evidence-based interdisciplinary guidelines with special emphasis on complementary and alternative therapies. Evid Based Complement Alternat Med. 2013;2013:485272. [PMID:24348701] http://dx.doi.org/10.1155/2013/485272
7. Clauw DJ. Fibromyalgia: A clinical review. JAMA. 2014;311(15):1547-55. [PMID:24737367] http://dx.doi.org/10.1001/jama.2014.3266

8. Fitzcharles MA, Ste-Marie PA, Goldenberg DL, Pereira JX, Abbey S, Choinière M, Ko G, Moulin DE, Panopalis P, Proulx J, Shir Y; National Fibromyalgia Guideline Advisory Panel. 2012 Canadian Guidelines for the diagnosis and management of fibromyalgia syndrome: Executive summary. Pain Res Manag. 2013;18(3):119-26. [PMID:23748251]

9. Institute of Medicine. Gulf war and health: Treatment for chronic multisymptom illness. Washington (DC): National Academies Press; 2013.

10. Zih FS, Da Costa D, Fitzcharles MA. Is there benefit in referring patients with fibromyalgia to a specialist clinic? J Rheumatol. 2004;31(12):2468-71. [PMID:15570653]

11. Gibson CA. Review of posttraumatic stress disorder and chronic pain: The path to integrated care. J Rehabil Res Dev. 2012;49(5):753-76. [PMID:23015584] http://dx.doi.org/10.1682/JRRD.2011.09.0158

12. American Psychiatric Association. Diagnostic and statistical manual of mental disorders-text revision (DSM-IVTR). Washington (DC): American Psychiatric Association; 2000.

13. Petzel RA. Decision support system outpatient identifiers. Washington (DC): Department of Veterans Affairs, Veterans Health Administration; 2013 May. Report No.: VHA Directive 1731.

14. Berger A, Dukes E, Martin S, Edelsberg J, Oster G. Characteristics and healthcare costs of patients with fibromyalgia syndrome. Int J Clin Pract. 2007;61(9):1498-1508. [PMID: 17655684] http://dx.doi.org/10.1111/j.1742-1241.2007.01480.x

15. Fitzcharles MA, Boulos P. Inaccuracy in the diagnosis of fibromyalgia syndrome: Analysis of referrals. Rheumatology (Oxford). 2003;42(2):263-67. [PMID:12595620]

http://dx.doi.org/10.1093/rheumatology/keg075

16. Frayne SM, Miller DR, Sharkansky EJ, Jackson VW, Wang F, Halanych JH, Berlowitz DR, Kader B, Rosen CS, Keane TM. Using administrative data to identify mental illness: What approach is best? Am J Med Qual. 2010;25(1):42-50. [PMID:19855046] http://dx.doi.org/10.1177/1062860609346347

17. Department of Veterans Affairs/Department of Defense. VA/DOD Clinical practice guideline for the management of chronic multisymptom illness, version 2.0 [Internet]. Washington (DC): Department of Veterans Affairs/Department of Defense; 2014 Oct. Available from: http:// www.healthquality.va.gov/guidelines/MR/cmi/ VADoDCMICPG.pdf

18. Seal KH, Shi Y, Cohen G, Cohen BE, Maguen S, Krebs EE, Neylan TC. Association of mental health disorders with prescription opioids and high-risk opioid use in US veterans 
of Iraq and Afghanistan. JAMA. 2012;307(9):940-47.

[PMID:22396516]

http://dx.doi.org/10.1001/jama.2012.234

19. Cohen BE, Gima K, Bertenthal D, Kim S, Marmar CR, Seal KH. Mental health diagnoses and utilization of VA non-mental health medical services among returning Iraq and Afghanistan veterans. J Gen Intern Med. 2010;25(1): 18-24. [PMID:19787409] http://dx.doi.org/10.1007/s11606-009-1117-3

20. Goldenberg DL. The interface of pain and mood disturbances in the rheumatic diseases. Semin Arthritis Rheum. 2010;40(1):15-31. [PMID:19217649] http://dx.doi.org/10.1016/j.semarthrit.2008.11.005

21. Buskila D, Cohen H. Comorbidity of fibromyalgia and psychiatric disorders. Curr Pain Headache Rep. 2007;11(5): 333-38. [PMID:17894922] http://dx.doi.org/10.1007/s11916-007-0214-4

22. Macciocchi SN. Conversion disorder presenting as primary fibromyalgia. Psychosomatics. 1993;34(3):267-70. [PMID:8493310] http://dx.doi.org/10.1016/S0033-3182(93)71890-3

23. Wilke WS, Gota CE, Muzina DJ. Fibromyalgia and bipolar disorder: A potential problem? Bipolar Disord. 2010;12(5): 514-20. [PMID:20712752] http://dx.doi.org/10.1111/j.1399-5618.2010.00848.x

24. Annemans L, Wessely S, Spaepen E, Caekelbergh K, Caubère JP, Le Lay K, Taïeb C. Health economic consequences related to the diagnosis of fibromyalgia syndrome. Arthritis Rheum. 2008;58(3):895-902. [PMID:18311794] http://dx.doi.org/10.1002/art.23265

25. Zou G. A modified poisson regression approach to prospective studies with binary data. Am J Epidemiol. 2004; 159(7):702-6. [PMID:15033648] http://dx.doi.org/10.1093/aje/kwh090

26. Department of Veterans Affairs/Department of Defense. VA/ DOD Clinical practice guideline for the management of opioid therapy for chronic pain, version 1.0. Washington (DC): Department of Veterans Affairs/Department of Defense; 2003.

27. Department of Veterans Affairs/Department of Defense. VA/DOD Clinical practice guideline for the management of opioid therapy for chronic pain, version 2.0 [Internet]. Washington (DC): Department of Veterans Affairs/Department of Defense; 2010 May. Available from: http:// www.healthquality.va.gov/guidelines/Pain/cot/ COT 312_Full-er.pdf

28. Midboe AM, Lewis ET, Paik MC, Gallagher RM, Rosenberg JM, Goodman F, Kerns RD, Becker WC, Trafton JA. Measurement of adherence to clinical practice guidelines for opioid therapy for chronic pain. Transl Behav Med. 2012;2(1):57-64. [PMID:24073098] http://dx.doi.org/10.1007/s13142-011-0104-5
29. Eisen SA, Kang HK, Murphy FM, Blanchard MS, Reda DJ, Henderson WG, Toomey R, Jackson LW, Alpern R, Parks BJ, Klimas N, Hall C, Pak HS, Hunter J, Karlinsky J, Battistone MJ, Lyons MJ; Gulf War Study Participating Investigators. Gulf War veterans' health: Medical evaluation of a U.S. cohort. Ann Intern Med. 2005;142(11):881-90. [PMID:15941694] http://dx.doi.org/10.7326/0003-4819-142-11-200506070-00005

30. Batuman F, Bean-Mayberry B, Goldzweig CL, Huang C, Miake-Lye IM, Washington DL, Yano EM, Zephyrin LC, Shekelle PG. Health effects of military service on women veterans. Washington (DC): Department of Veterans Affairs; 2001 May. Report No.: VA-ESP Project \# 05-226.

31. Edwards RR, Moric M, Husfeldt B, Buvanendran A, Ivankovich $\mathrm{O}$. Ethnic similarities and differences in the chronic pain experience: A comparison of African American, Hispanic, and white patients. Pain Med. 2005;6(1):8898. [PMID:15669954]

http://dx.doi.org/10.1111/j.1526-4637.2005.05007.x

32. Institute of Medicine. Relieving pain in America: A blueprint for transforming prevention, care, education and research. Washington (DC): The National Academies Press; 2011.

33. Goldenberg DL. Office management of fibromyalgia. Rheum Dis Clin North Am. 2002;28(2):437-46, xi.

[PMID:12122929]

http://dx.doi.org/10.1016/S0889-857X(01)00008-4

34. Lew HL, Otis JD, Tun C, Kerns RD, Clark ME, Cifu DX. Prevalence of chronic pain, posttraumatic stress disorder, and persistent postconcussive symptoms in OIF/OEF veterans: Polytrauma clinical triad. J Rehabil Res Dev. 2009; 46(6):697-702. [PMID:20104399] http://dx.doi.org/10.1682/JRRD.2009.01.0006

35. Raphael KG, Janal MN, Nayak S. Comorbidity of fibromyalgia and posttraumatic stress disorder symptoms in a community sample of women. Pain Med. 2004;5(1):33-41. [PMID:14996235] http://dx.doi.org/10.1111/j.1526-4637.2004.04003.x

36. Cohen H, Neumann L, Haiman Y, Matar MA, Press J, Buskila D. Prevalence of post-traumatic stress disorder in fibromyalgia patients: Overlapping syndromes or posttraumatic fibromyalgia syndrome? Semin Arthritis Rheum. 2002;32(1):38-50. [PMID:12219319] http://dx.doi.org/10.1053/sarh.2002.33719

37. Hoge CW, Auchterlonie JL, Milliken CS. Mental health problems, use of mental health services, and attrition from military service after returning from deployment to Iraq or Afghanistan. JAMA. 2006;295(9):1023-32. [PMID:16507803] http://dx.doi.org/10.1001/jama.295.9.1023

38. Sicras-Mainar A, Rejas J, Navarro R, Blanca M, Morcillo A, Larios R, Velasco S, Villarroya C. Treating patients with 
fibromyalgia in primary care settings under routine medical practice: A claim database cost and burden of illness study. Arthritis Res Ther. 2009;11(2):R54. [PMID:19366441] http://dx.doi.org/10.1186/ar2673

39. Smith GR Jr, Rost K, Kashner TM. A trial of the effect of a standardized psychiatric consultation on health outcomes and costs in somatizing patients. Arch Gen Psychiatry. 1995;52(3):238-43. [PMID:7872852]

http://dx.doi.org/10.1001/archpsyc.1995.03950150070012

Submitted for publication October 30, 2014. Accepted in revised form March 3, 2015.
This article and any supplementary material should be cited as follows:

Mohanty AF, Helmer DA, Muthukutty A, McAndrew LM, Carter ME, Judd J, Garvin JH, Samore MH, Gundlapalli AV. Fibromyalgia syndrome care of Iraq- and Afghanistan-deployed Veterans in Veterans Health Administration. J Rehabil Res Dev. 2016;53(1):45-58. http://dx.doi.org/10.1682/JRRD.2014.10.0265

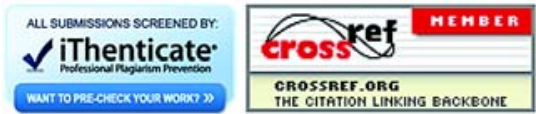


